\title{
Quality of life and general health in patients with temporomandibular disorders
}

\section{Camila Maria Bastos Machado de Resende $^{(a)}$ \\ Arthur César de Medeiros Alves ${ }^{(a)}$ Lidiane Thomaz Coelho(a) João Carlos Alchieri ${ }^{(b)}$ Ângelo Giuseppe Roncalli(a) Gustavo Augusto Seabra Barbosa $^{(a)}$}

\footnotetext{
(a) Department of Dentistry, Univ Federal do Rio Grande do Norte - UFRN, Natal, RN, Brazil.

(b) Department of Psychology, Univ Federal do Rio Grande do Norte - UFRN, Natal, RN, Brazil.
}

\begin{abstract}
The aim of this study was to associate minor psychiatric disorders (general health) and quality of life with temporomandibular disorders (TMD) in patients diagnosed with different TMD classifications and subclassifications with varying levels of severity. Among 150 patients reporting TMD symptoms, 43 were included in the present study. Fonseca's anamnestic index was used for initial screening while axis I of the Research Diagnostic Criteria for Temporomandibular Disorders (RDC-TMD) was used for TMD diagnosis (muscle-related, joint-related or muscle and joint-related). Minor psychiatric disorders were evaluated through the General Health Questionnaire (GHQ) and quality of life was assessed using the World Health Organization Quality Of Life-Brief Version (WHOQOL-BREF). An association was found between minor psychiatric disorders and TMD severity, except for stress. A stronger association was found with mild TMD. Considering TMD classifications and severity together, only the item "death wish" from the GHQ was related to severe muscle-related TMD ( $p=0.049$ ). For quality of life, an association was found between disc displacement with reduction and social domain $(\mathrm{p}=0.01)$. Physical domains were associated with TMD classifications and severity and the association was stronger for muscle and joint-related TMD ( $\mathrm{p}=0.037)$ and mild TMD $(\mathrm{p}=0.042)$. It was concluded that patients with TMD require multiple focuses of attention since psychological indicators of general health and quality of life are likely associated with dysfunction.
\end{abstract}

Descriptors: Psychosocial Impact; Quality of Life; Temporomandibular Joint Disorders.

\section{Introduction}

Temporomandibular disorder (TMD) is a muscle-skeletal painful disorder that compromises chewing muscles, temporomandibular joints (TMJs) and/or several anatomical structures in the stomatognathic system. ${ }^{1}$ These alterations lead to myofascial pain, disc displacement, joint pain and TMJ degeneration or inflammation. ${ }^{2}$

Considering the physical and functional limitations and different levels of morbidity caused by TMD, TMD etiological factors have been widely discussed in light of the development of better treatment protocols. It is known that TMD is a complex and multifactorial process and predisposing initiators and perpetrating factors decrease the physiologi-
Submitted: Oct 11, 2012

Accepted for publication: Dec 10, 2012

Last revision: Jan 03, 2013 
cal and structural threshold and increase dysfunctional severity. ${ }^{3}$

In general, physical, social and psychological factors are usually associated with TMD etiology. This information about TMD development and maintenance is important in defining a biopsychosocial model for TMD. ${ }^{4}$

Based on the current etiological concepts, physical and systemic conditions as well as psychological factors are responsible for targeting and maintaining TMD. Stress, depression and anxiety change the individual's threshold for pain through alteration of nociceptive impulses from the central nervous system and release of neurotransmitters. ${ }^{5}$ In addition, these psychological alterations increase the frequency, intensity and duration of parafunctional habits, such as tooth clenching and bruxism, which cause hyperactivity of chewing muscles, TMJ overloading and higher patient morbidity. ${ }^{6,7}$

Furthermore, pain and stress associated with TMD represent a negative influence on systemic health and quality of life, which compromise daily social activities at school or work, social functions, affective and cognitive equilibrium, sleep and physical activities. ${ }^{8}$

Considering a possible relation between psychosocial factors and TMD and the influence of various variables on TMD treatment, the aim of this study was to assess alterations of the indicators of quality of life, general health (minor psychiatric disorders) and anxiety of patients diagnosed with different TMD classifications.

\section{Methodology Subjects}

Initially, 150 patients attending the Department of Dentistry at the Federal University of Rio Grande do Norte with complaints of TMD signs and symptoms were considered for this study. Among these patients, 60 (53 females and 7 males, mean age 36.48 years) were assessed to have some level of TMD after screening with Fonseca's anamnestic index. ${ }^{9}$ However, only 43 patients were diagnosed with TMD through the Research Diagnostic Criteria for Temporomandibular Dysfunction (RDCTMD) method and met the eligibility and exclusion criteria for the present study.

The research was conducted at the Center for Treatment of Patients with Stomatognathic System Dysfunction in the Department of Dentistry. The study was approved by the Ethics Committee in Research of the Federal University of Rio Grande do Norte (CEP-UFRN; protocol 039/08). All volunteers agreed to participate and informed consent was obtained from all subjects.

\section{Eligibility and exclusion criteria}

The eligibility criteria for the study consisted of some level of TMD severity (mild, moderate and severe TMD) after screening with the Fonseca's anamnestic index (Fonseca et al.). ${ }^{9}$ This index is a selfadministered questionnaire with ten questions about TMD symptoms. This tool is used for patient screening and has demonstrated a $95 \%$ correlation with Helkimo's anamnestic index in patients with TMD. ${ }^{10}$

The exclusion criteria consisted of patients without a positive diagnosis of TMD by the RDC-TMD method. Patients with systemic health disorders, such as neurological disorders, fibromyalgia, neuralgia or headache, earache and those that received recent surgeries were also excluded to avoid confusions with TMD symptoms.

\section{Procedures}

The patients previously screened by Fonseca's anamnestic index performed the RDC-TMD ${ }^{11}$ axis I for TMD classification. The RDC-TMD method is a diagnostic tool for physical evaluation of the patient through 10 items of clinical exam and 3 subjective questions. The individuals are classified into one of the three TMD diagnostic groups:

- group I (myofascial pain and myofascial pain with limited opening),

- group II (disc displacement with reduction, disc displacement without reduction and disc displacement without reduction with limited opening) and

- group III (arthralgia, osteoarthritis and osteoarthrosis).

The RDC axis II was replaced by two psychological tools more specific to the aim of this study. 
For didactic purposes, groups II and III were combined into the joint-related TMD classification while group I represented the muscle-related TMD classification. A coincidence between group I and group II and/or group III was classified as muscle and joint-related TMD.

The General Health Questionnaire (GHQ) $)^{12}$ was used for evaluation of general health. This questionnaire analyzes mental health through the presence or absence of non-psychotic psychiatric disorders (minor psychiatric disorders). ${ }^{13}$ It consists of 60 questions divided into six factors:

- psychological stress,

- death wish,

- distrust in self performance,

- sleep disturbances,

- psychosomatic disorders and

- general health.

The patients were instructed to always answer about their current psychological status.

For evaluation of quality of life, the World Health Organization Quality Of Life-Brief Version (WHOQOL-BREF) ${ }^{14,12}$ was used as a specific tool. This test contained 26 questions divided into four domains:

- physical,

- psychological,

- social and

- environmental.

In addition to all methods previously described, a voice recorder was used to register a subjective report about the main complaints of each patient.

\section{Statistics}

A database was created with SPSS 15.0 for Windows (SPSS Inc., Chicago, USA). A Kruskal-Wallis test was conducted to assess the difference between the means of dependent variables of the groups. The six clinical factors crossed with the psychological aspects (quality of life and general health) included groups I, II and III of the RDC-TMD, which were evaluated separately as TMD classification (musclerelated, joint-related, and muscle and joint-related), TMD severity (mild, moderate and severe), and
TMD classification and severity (mild, moderate and severe muscle-related; mild, moderate and severe joint-related; mild, moderate and severe muscle and joint-related). It is important to state that, after verifying that males constituted a small portion of the sample $(\mathrm{n}=7)$, inferential statistical analysis was not conducted including males since it would work as an element with high magnitude. Thus, the final sample consisted of 43 volunteers.

\section{Results}

Among the TMD classifications, there was a higher number of individuals in the muscle and joint-related TMD group $(\mathrm{n}=30)$, followed by the joint-related group $(\mathrm{n}=9)$ and the muscle-related group $(\mathrm{n}=4)$.

Considering the presence of minor psychiatric disorders, none of the six GHQ dimensions was associated with a TMD classification. However, there was an association between minor psychiatric disorders and TMD severity, except for the factor "stress". In general, a stronger association was found with mild TMD (Table 1).

Table 1 - Association between TMD severity and minor psychiatric disorders.

\begin{tabular}{|c|c|c|c|}
\hline $\mathrm{GHQ}^{* *}$ & TMD severity & Mean points & $*_{p}$ \\
\hline \multicolumn{3}{|l|}{ Stress } & 0.078 \\
\hline \multirow{3}{*}{ Death } & Mild TMD & 31.75 & \multirow{3}{*}{0.018} \\
\hline & Moderate TMD & 20.61 & \\
\hline & Severe TMD & 17.98 & \\
\hline \multirow{3}{*}{ Performance } & Mild TMD & 33.63 & \multirow{3}{*}{0.049} \\
\hline & Moderate TMD & 27.06 & \\
\hline & Severe TMD & 18.1 & \\
\hline \multirow{3}{*}{ Sleep } & Mild TMD & 29.75 & \multirow{3}{*}{0.016} \\
\hline & Moderate TMD & 27.78 & \\
\hline & Severe TMD & 18.41 & \\
\hline \multirow{3}{*}{ Somatic } & Mild TMD & 30.88 & \multirow{3}{*}{0.016} \\
\hline & Moderate TMD & 29.06 & \\
\hline & Severe TMD & 17.86 & \\
\hline \multirow{3}{*}{ Health } & Mild TMD & 34.75 & \multirow{3}{*}{0.042} \\
\hline & Moderate TMD & 26.39 & \\
\hline & Severe TMD & 18.16 & \\
\hline
\end{tabular}

*Kruskall-Wallis test ( $p \leq 0.05),{ }^{* *}$ General Health Questionnaire. 
Table 2 - Association between group II of RDC-TMD and quality of life.

\begin{tabular}{|c|c|c|c|}
\hline WHOQOL*** & Group II- RDC-TMD & Mean points & ${ }^{*} p$ \\
\hline \multicolumn{3}{|l|}{ Physical } & 0.79 \\
\hline \multicolumn{3}{|l|}{ Psychological } & 0.17 \\
\hline \multirow{4}{*}{ Social } & No diagnosis & 20.63 & \multirow{4}{*}{0.01} \\
\hline & $\mathrm{DD}^{* *}$ with reduction & 35.03 & \\
\hline & $\begin{array}{l}\text { DD without reduction } \\
\text { and without limitation }\end{array}$ & 30 & \\
\hline & $\begin{array}{l}\text { DD without reduction } \\
\text { and with limitation }\end{array}$ & 15 & \\
\hline \multicolumn{3}{|l|}{ Environmental } & 0.17 \\
\hline
\end{tabular}

For quality of life, an association was found in group II of RDC-TMD with social domain and a stronger association was found with disc displacement with reduction ( $\mathrm{p}=0.01$; Table 2$)$. Physical domain was associated with both TMD classification (Table 3) and severity (Table 4) and it was stronger in the groups with muscle and joint-related TMD $(\mathrm{p}=0.037)$ and mild TMD ( $\mathrm{p}=0.042)$.

\section{Discussion}

The reported prevalence of TMD has varied greatly from one study to another and also within the population studied. ${ }^{13-18}$ Moreover, epidemiological studies usually assess the prevalence of TMD signs and symptoms but not the cases actually diagnosed as dysfunctional. In this study, the sample size was small when the diagnostic subclassifications of RDC-TMD were considered.

Some studies ${ }^{19-21}$ in the literature assessed depression, anxiety and pain in patients with TMD. Although these studies did not analyze general health indicators, a trend was observed that patients with muscle pain exhibited more psychological problems, poor quality of sleep and a greater number of stress agents. ${ }^{5,6,22,23}$ Similarly, Manfredini et al. ${ }^{23}$ used the RDC-TMD and found that group I with a TMD diagnosis (myofascial pain) was associated more with psychological factors (mood disorders and fear of open spaces and crowds) than the other TMD subclassifications. Auerbach et al. ${ }^{20}$ also concluded that psychological factors play a more important role in
Table 3 - Association between TMD classification and quality of life.

\begin{tabular}{l|c|c|c}
\hline WHOQOL** & TMD classification & Mean points & ${ }^{*} \mathrm{p}$ \\
\hline \multirow{3}{*}{ Physical } & muscle-related TMD & 15.91 & \multirow{2}{*}{0.037} \\
\cline { 2 - 3 } & $\begin{array}{c}\text { joint-related TMD } \\
\text { muscle and } \\
\text { joint-related TMD }\end{array}$ & 23.18 & \\
\hline Psychological & 28.69 & 0.698 \\
\hline Social & & 0.612 \\
\hline Environmental & 0.069 \\
\hline
\end{tabular}

*Kruskall-Wallis test $(p \leq 0.05),{ }^{* *}$ World Health Organization Quality Of Life.

Table 4 - Association between TMD severity and quality of life.

\begin{tabular}{l|c|c|c}
\hline WHOQOL** $^{*}$ & TMD severity & Mean points & ${ }^{*} \mathrm{p}$ \\
\hline \multirow{3}{*}{ Physical } & Mild TMD & 28.38 & \multirow{2}{*}{0.042} \\
\cline { 2 - 3 } & Moderate TMD & 22.61 & \\
\cline { 2 - 3 } & Severe TMD & 12.72 & \\
\hline Psychological & & 0.453 \\
\hline \multicolumn{2}{|l}{ Social } & & 0.320 \\
\hline \multicolumn{2}{l|}{ Environmental } & & 0.394 \\
\hline
\end{tabular}

*Kruskall-Wallis test $(p \leq 0.05),{ }^{* *}$ World Health Organization Quality Of Life.

pain of muscular origin.

Considering the findings of the present study, none of the six psychological factors assessed by the GHQ were associated with classifications and subclassifications of RDC-TMD but were associated with TMD severity. Previous studies in the literature usually associated stress with TMD classifications ${ }^{20,19}$ but not with severity.

In the present study, the indicators of psychological disorders demonstrated a greater association with mild TMD, except for the factor "stress" (Table 1). Considering that TMD severity evolves gradually, it may cause morbidity, psychological alterations, sleep dysfunction, difficulty to perform daily activities and problems in general health. The evolution to moderate or severe dysfunction may be accompanied by different behaviors in an attempt to tolerate its consequences, resulting in a lower association with the GHQ.

Quality of life should be evaluated according to 
a personal perception of one's own health condition, including general aspects of life and well-being and also subjective experiences within the cultural context. ${ }^{24}$ Objective measurements of disease provide few answers about the impact of oral conditions on daily life and quality of life. ${ }^{19}$ This information highlights the importance of diagnosing psychosocial factors that may be involved in the disease.

Several published studies evaluating quality of life through the Oral Health Impact Profile (OHIP) can be found in the literature. ${ }^{25-27}$ Reissmann et al. ${ }^{2}$ used the RDC-TMD as a diagnostic tool and found that patients with myofascial pain exhibited a greater impact on quality of life than the other groups according to the OHIP questionnaire. However, the present results demonstrated that quality of life was associated with Group II of RDC-TMD and showed a stronger association with disc displacement with reduction (Table 2). The difference between results is likely a consequence of different methodologies. The OHIP is a more specific tool for assessing the impact of oral health on quality of life while the WHOQOL is a questionnaire that is not restricted to oral conditions.

The results of the present study on quality of life showed that disc displacement with reduction was the only diagnosis subclassification of RDC-TMD with a statistically significant association with social domain. Considering the common signs and symptoms of this dysfunction, clicks while chewing and limited function can compromise social behavior, including group activities. According to patient reports, frequent clicks during chewing in public spaces limited social life. When the TMD classifications were evaluated (Table 3), it was observed that the strongest association occurred between muscle-

\section{References}

1. Tjakkes GE, Reinders J, Tenvergert EM, Stegenga B. TMD pain: the effect on health related quality of life and the influence of pain duration. Health Qual Life Outcomes. 2010 May;8(46):1-8.

2. Reissmann DR, John MT, Schierz O, Wassell RW. Functional and psychosocial impact related to specific temporomandibular disorder diagnoses. J Den. 2007 Aug; 35(8):643-50. joint related TMD and physical domain. Therefore, in this group, it can be concluded that pain and discomfort lead to greater physiological expression and energy perception.

When TMD severity was analyzed (Table 4), physical domain was also associated with psychological factors, which indicated a greater perception of physical impairment caused by dysfunction. No other studies evaluated the association between dysfunctional severity and quality of life.

Further studies, including systematic reviews ${ }^{28}$ and analytical studies ${ }^{29}$ involving the influence of psychological interventions on TMD treatment, are essential for understanding the role of psychosocial aspects on dysfunction etiology and consequences. It is important to note that the present study has some limitations and the results are within a specific context. In addition, the sample size became small when the subclassification of RDC-TMD was considered. For evaluation of TMD severity, the length of pain experience and the occurrence of any previous treatment should be considered with any association between quality of life and TMD. Therefore, additional studies associating pain and quality of life are required.

Certainly, improvements in methodology will contribute to future research, furthering better TMD treatment. Moreover, multidisciplinary integration is essential for treatment efficacy and a humanized approach.

\section{Conclusions}

This study demonstrated that patients with TMD require multiple focuses of attention since psychological indicators of general health and quality of life are associated with dysfunction.

3. Sharma S, Gupta DS, Pal US, Jurel SK. Etiological factors of temporomandibular joint disorders. Natl J Maxillofac Surg. 2011Jul;2(2):116-9.

4. Dougall AL, Jimenez CA, Haggard RA, Stowell AW, Riggs RR, Gatchel RJ. Biopsychosocial factors associated with the subcategories of acute temporomandibular joint disorders. J Orofac Pain. 2012 Winter;26(1):7-16. 
5. Bertoli E, De Leeuw R, Schmidt JE, Okeson JP, Carlson CR. Prevalence and impact of post-traumatic stress disorder symptoms in patients with masticatory muscle or temporomandibular joint pain: differences and similarities. J Orofac Pain. 2007 Spring;21(2):107-19.

6. Bonjardim LR, Gavião MB, Pereira LJ, Castelo PM. Anxiety and depression in adolescents and their relationship with signs and symptoms of temporomandibular disorders. Int J Prosthodont. 2005 Jul-Aug;18(4):347-52.

7. Monteiro DR, Zuim PRJ, Pesqueira AA, Ribeiro PP, Garcia AR. Relationship between anxiety and chronic orofacial pain of temporomandibular disorder in a group of university students. J Prosthodont Res. 2011 Jul;55(3):154-8.

8. Oliveira AS, Bermudez CC, Souza RA, Souza CMF, Dias RM, Castro CES, et al. [Pain impact on life of patients with temporomandibular disorder]. J Appl Oral Sci. 2003 AprJun;11(2):138-43. Portuguese.

9. Fonseca DM, Bonfante G, Valle AL, Freitas SFT. Diagnóstico pela anamnese da disfunção craniomandibular. Rev Gaucha Odontol. 1994 Jan-Fev;42(1):23-8.

10. Bevilaqua-Grossi D, Chaves TC, Oliveira AS, Monteiro-Pedro V. Anamnestic index severity and signs and symptoms of TMD. Cranio. 2006 Apr;24(2):112-18.

11. Dworkin SF, LeResche L. Research diagnostic criteria for temporomandibular disorders: review, criteria, examinations and specifications, critique. J Craniomandib Disord. 1992 Fall;6(4):301-55.

12. Goldberg D. The detection of psychiatric illness by questionnaire. London: Oxford University Press; 1972.

13. Pasquali L, Gouveia VV, Andriola WB, Miranda FJ, Ramos ALM. [General Health Questionnaire of Goldberg (QSG): Brazilian adaptation]. Psicol Teoria Pesqui. 1994 SetDez;10:421-37. Portuguese.

14. Fleck MPA, Leal OF, Louzada S, Xavier M, Chachamomovich E, Vieira G, et al. [Development of the Portuguese version of the WHO evaluation instrument of quality of life (WHOQOL-100)]. Rev Bras Psiquiatr. 1999 Mar;21(1):19-28. Portuguese.

15. WHOQOL Group. The World Health Organization quality of life assessment (WHOQOL): position paper from the World Health Organization. Soc Sci Med. 1995 Nov;41(10):1403-9.

16. Carlsson GE. Epidemiological studies of signs and symptoms of temporomandibular joint-pain-dysfunction. Aust Prosthodont Soc Bull. 1984;14(12):7-12.

17. McNeill C, Danzig WM, Farrar WB, Gelb H, Lerman MD, Moffett BC, et al. Position paper of the American Academy of Craniomandibular Disorders. Craniomandibular (TMJ) disorders - the state of the art. J Prosthet Dent. 1980 Oct;44(4):434-7.
18. Schiffman EL, Fricton JR, Haley DP, Shapiro BL. The prevalence of treatment needs of subjects with temporomandibular disorders. J Am Dent Assoc. 1990 Mar;120(3):295-303.

19. Dworkin SF, Massoth DL. Temporomandibular disorders and chronic pain: disease or illness?. J Prosthet Dent. 1994 Jul;72(1):29-38.

20. Auerbach SM, Laskin DM, Frantsve LM, Orr T . Depression, pain, exposure to stressful life events, and long-term outcomes in temporomandibular disorder patients. J Oral Maxillofac Surg. 2001 Jun;59(6):628-33.

21. Kino K, Sugisaki M, Haketa T, Amemori Y, Ishikawa T, Shibuya $\mathrm{T}$, et al. The comparison between pains, difficulties in function, and associating factors of patients in subtypes of temporomandibular disorders. J Oral Rehabil. 2005 May;32(5):315-25.

22. Lindroth JE, Schmidt JE, Carlson CR. A comparison between masticatory muscle pain patients and intracapsular pain patients on behavioral and psychosocial domains. J Orofac Pain. 2002 Fall;16(4):277-83.

23. Manfredini D, Bandettini PA, Cantini E, Dell'osso L, Bosco M. Mood and anxiety psychopathology and temporomandibular disorder: a spectrum approach. J Oral Rehabil. 2004 Oct;31(10):933-40.

24. Christensen GJ. Now is the time to observe and treat dental occlusion. J Am Dent Assoc. 2001 Jan;132(1):100-2.

25. John MT, Miglioretti DL, LeResche L, Koepsell TD, Hujoel P, Micheelis W. German short forms of the Oral Health Impact Profile. Community Dent Oral Epidemiol. 2006 Aug;34(4):277-88.

26. Jedel E, Carlsson J, Stener-Victorin E. Health-related quality of life in child patients with temporomandibular disorder pain. Eur J Pain. 2007 Jul;11(5):557-63.

27. Türp JC, Motschall E, Schindler HJ, Heydecke G. In patients with temporomandibular disorders, do particular interventions influence oral health-related quality of life? A qualitative systematic review of the literature. Clin Oral Implants Res. 2007 Jun;18(3):127-37.

28. Aggarwal VR, Lovell K, Peters S, Javidi H, Joughin A, Goldthorpe J. Psychosocial interventions for the management of chronic orofacial pain. Cochrane Database Syst Rev. 2011 Nov 9;(11):CD008456. doi: 10.1002/14651858.CD008456. pub2.

29. Liao CH, Chang CS, Chang SN, Lane HY, Lyu SY, Morisky $\mathrm{DE}$, et al. The risk of temporomandibular disorder in patients with depression: a population-based cohort study. Community Dent Oral Epidemiol. 2011 Dec;39(6):525-31. 